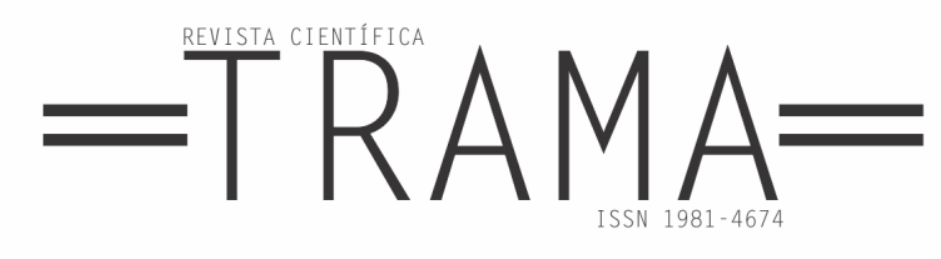

\title{
UMA OUTRA CULTURA DE APRENDIZAGEM? \\ FATORES DETERMINANTES PARA A APRENDIZAGEM DE LÍNGUAS ESTRANGEIRAS NA ALEMANHA
}

\section{Paul VOERKEL ${ }^{1}$}

Resumo: $O$ objetivo deste artigo é apresentar, em linhas gerais, alguns fatores que influenciam a forma de aprender línguas estrangeiras na Alemanha. Um fator central é a política proativa de fomento às línguas, a nível europeu, que existe há mais de 40 anos e que determina tanto a forma do processo educativo, quanto o valor que a sociedade atribui ao domínio das línguas estrangeiras. No caso da Alemanha, esta orientação tem dado resultados positivos, o que finalmente aponta para a relevância de se discutir ativamente o papel do multilinguismo no ensino de línguas estrangeiras no Brasil.

Palavras-chave: ensino-aprendizagem; língua estrangeira; alemão.

\begin{abstract}
The goal of this article is a description of some of the factors that underlie processes of foreign language acquisition in Germany. One of the main factors to be mentioned is the common European politics on language support which can be observed for more than 40 years and determines both the education processes and the value given by the main part of society to the knowledge of foreign languages. In Germany, this orientation has led to good results, which at the end leads to the idea of discussing the positive influence of multilinguism as well in the case of foreign language education in Brazil.
\end{abstract}

Keywords: Learning process; foreign language learning; German.

Recebido em 31-08-2017 Aceito em 12-12-2017

\footnotetext{
${ }^{1}$ Universidade Federal do Rio de Janeiro (UFRJ), Deutscher Akademischer Austauschdienst (DAAD).
} 


\section{$=$ TRAMA $=$}

\section{Introdução}

A constituição atual do Brasil entrou em vigor em 1988 e, até o presente ano $^{2}$, passou por inúmeras alterações, respaldadas por quase cem emendas constitucionais. Dentre os poucos artigos da constituição que não sofreram quaisquer alterações nos últimos trinta anos, encontra-se o artigo 13, no qual é assegurado que "A língua portuguesa é o idioma oficial da República Federativa do Brasil." (cf. SUPREMO TRIBUNAL FEDERAL, 2017, p. 28). No entanto, observando as relações cotidianas que os estrangeiros vivenciam ao visitar o país, nota-se que a língua portuguesa não só é o idioma oficial, como também é, na maior parte das vezes, o único idioma que permite comunicar-se com os brasileiros ${ }^{3}$. Diante de tais circunstâncias, os estrangeiros - principalmente aqueles que permanecem no país durante um período mais extenso - que querem e necessitam interagir com as pessoas do local, precisam aprender a falar português.

Neste contexto, não é incomum que alemães ${ }^{4}$ que residem no Brasil recebam elogios sobre o domínio da língua portuguesa, bem como comentários sobre a facilidade com que os europeus aprenderiam idiomas estrangeiros. Ainda mais frequentes são as opiniões dos brasileiros sobre suas próprias habilidades linguísticas, nas quais eles demonstram bastante incredulidade quanto à apropriada aprendizagem de alemão e sua utilização em níveis avançados. Esta atitude de se sentir numa posição inferior aos outros ganhou,

\footnotetext{
${ }^{2}$ A listagem com as emendas encontra-se na publicação do Supremo Tribunal Federal de 2017. indicada nas referências bibliográficas. Outra lista com data da mudança e o conteúdo das emendas pode ser consultada na página: http://www.planalto.gov.br/ccivil_03/constituicao/constituicao.htm (acesso em 11/11/2017).

${ }^{3}$ De fato, existe um número elevado de outras línguas faladas no país (cf. Dornelles 2011: 25-
}

na literatura, o nome de "complexo de vira-lata", e foi descrito como "a inferioridade em que o brasileiro se coloca, voluntariamente, em face do resto do mundo" (JOFFILY, 2013, p. 70).

Para explicar a deficiência no conhecimento de idiomas estrangeiros no país, é frequente que os interlocutores recorram à situação das escolas públicas, caracterizadas pelas dificuldades financeiras, a evasão de parte importante do alunado e o grau de instrução - principalmente na área de línguas - deficitário entre os docentes (cf. GUASCO PEIXOTO, 2013, p. 107; KAUFMANN, 2003, p. 32; RICHTER, 2013, p. 185189). A situação destas instituições, onde o ensino é considerado insuficiente e deficitário, diferencia-se consideravelmente daquela encontrada em escolas particulares e instituições privadas de ensino de língua, como os institutos Goethe, onde as pessoas aceitam pagar mensalidades altas com a expectativa de "aprender a língua de verdade".

Essas observações levam a uma série de perguntas: será que entre brasileiros e alemães existem diferenças no talento para aprender idiomas estrangeiros? As aulas de línguas estrangeiras possuem características diferentes? Ou será que os resultados da aquisição de línguas dependem mais do posicionamento da sociedade e da estruturação das escolas?

A primeira pergunta é relativamente fácil de responder: estudos apontam que não existem diferenças empiricamente relevantes concernentes à habi-

30). Também existem pessoas que falam outros idiomas - porém, são relativamente poucas, e depende muito da região e do nível de instrução.

${ }^{4}$ Essa afirmação poderia estar referida a qualquer cidadão estrangeiro cuja língua materna não seja o português. Porém, tratando-se de um artigo sobre a interação com a língua alemã, recorreu-se a este exemplo. 


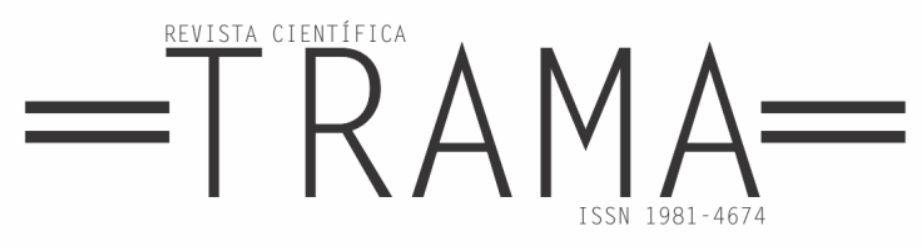

lidade para aprendizagem de línguas estrangeiras (LE), nem entre pessoas de um mesmo país, nem quando comparamos alunos de países diferentes (cf. RÖSLER, 2012, p. 8). Por outro lado, afirmase cada vez mais a forte influência de algumas abordagens e medidas a respeito da aprendizagem de línguas estrangeiras e os resultados que se obtêm nas aulas. $\mathrm{Na}$ atualidade é reconhecido o papel importante das políticas linguísticas para a criação de atitudes positivas frente às línguas estrangeiras, à oferta das línguas na sociedade e aos resultados obtidos em sala de aula (cf. BUSSE, 2017, p. 56; KRUMM, 2016ª , p. 45).

Com este pano de fundo, o presente artigo pretende desconstruir o mito de que existe um "talento europeu para aprender línguas estrangeiras" (cf. HUNEKE, STEINIG, 2013, 22f.). Para tanto, pretende-se mostrar, através da descrição em linhas gerais da situação na Alemanha, a grande influência dos fatores exógenos que interferem nos processos de aprendizagem (cf. ROCHE 2008, p. 42).

\section{Aprender línguas estrangeiras na Alemanha}

Na Alemanha, a aprendizagem de línguas estrangeiras passou por diferentes momentos históricos em que se entrelaçam sociedade, cultura e a política do país. Enquanto o estudo do latim (e parcialmente também do grego e do hebraico) foi obrigatório para o clero durante séculos e até hoje tem um papel importante na formação histórico e religioso, as chamadas "línguas vivas" foram aprendidas, desde o século XVI, principalmente pelos nobres e alguns poucos

\footnotetext{
${ }^{5} \mathrm{Na}$ Alemanha foi utilizada, desde o século XIX, a distinção entre "altsprachlich" e "neusprachlich" (cf. Reinfried 2016: 619), isto é, "línguas mortas" (sem uso na comunicação oral, como
}

comerciantes, ou seja, por uma pequena parcela da sociedade (cf. REINFRIED, 2016, p. 620). Paulatinamente, seguindo os ideais iluministas, esta situação começou a mudar durante o século XVIII, quando muitos burgueses que residiam nas cidades passaram a ter acesso à educação, sendo contemplada inclusive a aprendizagem de línguas estrangeiras.

Posteriormente, durante a primeira metade do século XIX, nota-se drástica mudança a partir da introdução da escolaridade obrigatória em terras alemãs. Desta época deriva a separação relativamente rigorosa dos ramos da escolaridade. Os jovens alunos passam a ser separados em diferentes tipos de instituições por volta dos dez anos de idade, conforme o grau de instrução: na Volksschule (ou Hauptschule) é oferecida a educação básica, dando acesso restrito ao mercado laboral; a Realschule (ou Mittelschule), por sua vez, dispõe a educação técnica para futura atuação em profissões como comércio e serviço público e, por fim, há o Gymnasium, que permite o acesso à educação superior (cf. PRECHT, 2013, p. 51). Vale a pena ressaltar que a aquisição de línguas estrangeiras, até meados do século $\mathrm{XX}$, só se deu no Gymnasium, instituição que pela alta exigência foi frequentada geralmente por menos de $10 \%$ dos jovens. Mesmo cobrindo só uma faixa relativamente pequena da sociedade, foi com este tipo de escola que se garantia a integração da aprendizagem de línguas no setor escolar, incluindo a criação de currículos e metodologias elaboradas de ensino e de formação de professores (cf. PRECHT, 2013, p. 38; REINFRIED, 2016, p. 621).

grego antigo e latim) e "línguas vivas" (utilizadas na comunicação atual entre pessoas e na vida cotidiana). 


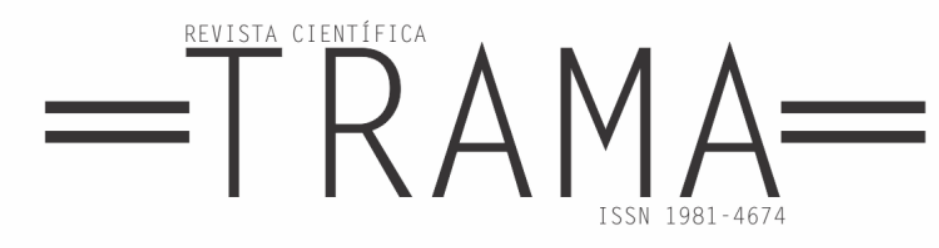

Outro passo decisivo para a democratização da aprendizagem de idiomas estrangeiros na Alemanha foram as grandes reformas dos governos socialdemocratas dos anos 1960 e 1970. As mudanças implementadas por este governo foram motivadas, por um lado, pelos laços econômicos cada vez mais estreitos entre os países europeus (fenômeno que requeria competências linguísticas de grande parte das pessoas), mas por outro lado pelas deficiências do sistema educativo da época que excluía uma faixa elevada dos jovens da educação superior (cf. PICHT, 2013, p. 51). Neste contexto, não só o número de universidades e de vagas para estudantes subiu exponencialmente, como também a quantidade e a qualidade do ensino. Desde então, o tempo mínimo de escolaridade subiu de seis para nove anos, e em todos os tipos de escola foi instituída a obrigatoriedade da oferta de aulas de, no mínimo, uma língua estrangeira a partir do $5^{\circ}$ ano, portanto, desde os onze anos de idade, aproximadamente (cf. DE CILLIA, KLIPPEL, 2016, p. 625). No Gymnasium, hoje em dia frequentado por quase a metade dos jovens alemães, é obrigatório aprender duas línguas estrangeiras, sendo comum ofertar aos alunos uma $3^{\mathrm{a}}$ ou até $4^{\mathrm{a}}$ língua estrangeira na grade curricular. Para a realização da

\footnotetext{
${ }^{6} \mathrm{O}$ Abitur é uma prova obrigatória para conclusão do ensino médio e para entrar na universidade. Como as universidades não regulam a entrada dos calouros através de uma prova de admissão (o que no Brasil seria o vestibular), mas sim pela nota do Abitur, esta prova tem um significado muito importante, tanto para os alunos, quanto para as escolas e universidades.

${ }^{7}$ A imigração, seja por motivos de trabalho, de estudos ou de busca de asilo, elevou o número de estrangeiros residentes na Alemanha para além de $10 \%$, atingindo em alguns municípios quase a metade da população.

${ }^{8}$ Esta nova perspectiva entrou nas universidades também: além da oferta da disciplina acadêmica
}

prova do $A b i t u{ }^{6}$, é obrigatório pelo menos uma língua estrangeira (cf. DE CILLIA, KLIPPEL, 2016, p. 626).

Ainda sobre os fatores que contribuíram para que o ensino de línguas estrangeiras fosse consolidado, vale mencionar um outro fenômeno: a partir dos anos 1960, a Alemanha se tornou um país de imigração. Nos dois lados do país, naquela época separado pela "cortina de ferro", chegaram milhares de pessoas em busca de oportunidades de estudos e de trabalho, dos quais uma faixa importante decidiu instalar-se no país anfitrião de modo permanente ${ }^{7}$. A aprendizagem de línguas estrangeiras aconteceu, portanto, não só pela perspectiva alemã, mas também pela perspectiva dos imigrantes que vivem no meio dos falantes da língua-alvo ${ }^{8}$.

Levando em consideração o contexto atual, podemos nomear dois pontos centrais atuantes no ensino de línguas estrangeiras na Alemanha. Em primeiro lugar, encontramos o setor escolar, serviço eminentemente público, onde toda criança a partir dos onze anos ${ }^{9}$ estabelece contato intensivo com uma ou duas línguas estrangeiras de quatro a cinco horas semanais, em média. Sendo assim, quando um jovem se prepara para entrar na universidade e vai prestar o Abitur, ele já estudou no mínimo durante oito anos a primeira língua estrangeira, ou seja, por mais de 1.200 horas, além dos quatro

\footnotetext{
“Alemão como Língua Estrangeira” (ALE), criada ao longo dos anos 1960 nas universidades, houve também a partir da década de 1980 a ampliação da oferta da disciplina "Alemão como Segunda Língua” (ASL), com o propósito de responder aos desafios da demanda cada vez mais elevada por parte de pessoas não nativas.

${ }^{9}$ Muitas escolas passaram a oferecer a primeira língua estrangeira durante o Ensino Fundamental I (Grundschule), isto é, a partir dos sete anos de idade. Isto indica que cada vez mais jovens aprendem línguas estrangeiras durante doze anos. A obrigatoriedade do ensino, no entanto, só vale a partir do Ensino Fundamental II (cf. Rymarczyk, Vogt 2016: 68).
} 


\section{$=$ TRAMA $=$}

anos obrigatórios de outra língua estrangeira. Na maioria das escolas é oferecido inglês como primeira língua estrangeira e francês, espanhol, italiano, russo e latim como outros idiomas das grades curriculares ${ }^{10}$ (cf. RYMARCZYK, VOGT, 2016, p. 68).

O outro ponto que deve ser considerado importante, diz respeito à existência de ofertas variadas para aprendizagem de idiomas estrangeiros fora do âmbito escolar. Instituições municipais ou estaduais oferecem inúmeros tipos de cursos a preços acessíveis. A maior oferta neste setor encontra-se nos centros de educação para adultos (Volkshochschule), abertos para o público em geral. Dentre eles há oferta de idiomas que não fazem parte dos currículos escolares, tal como sueco, chinês, assim como português. Principalmente para o ensino do ASL pode-se contar com uma rede cada vez mais ampla de institutos privados voltados ao ensino de línguas.

Para aprofundar as reflexões sobre a frequência, a forma e a função da aprendizagem de línguas estrangeiras na Alemanha, é necessário apontar várias outras temáticas relevantes. Primeiramente, destacamos o papel determinante das políticas públicas de fomento às línguas, vigentes na Europa há mais de quarenta anos, que estruturam a forma como o ensino é oferecido e, consequentemente, reverberam no desempenho dos alunos nos processos de aprendizagem de línguas estrangeiras, assim como nos resultados obtidos enquanto domínio efetivo dessas línguas.

\footnotetext{
${ }^{10}$ Além das línguas mencionadas, são oferecidas outras línguas estrangeiras nas escolas alemãs, tais como árabe, chinês ou sueco. Entretanto, são pouquíssimas opções e usualmente são aulas facultativas, fora da grade curricular. No caso da língua portuguesa, por exemplo, existe a oferta
}

\section{papel das políticas europeias}

O continente europeu tem basicamente a mesma superfície que o Brasil, mas reúne aproximadamente cinquenta países com 24 línguas oficiais e mais de 120 línguas minoritárias. Esta ampla heterogeneidade se constituiu com a criação dos Estados-nação, que foram em grande parte estabelecidos com base em língua e cultura comuns (cf. KRUMM, 2016b, p. 633). No entanto, após passar por duas guerras devastadoras e posteriormente ser influenciado pela tendência mundial à globalização, o continente mudou radicalmente nas últimas décadas. Atualmente, ainda que não haja consenso acerca do assunto, é marcante na Europa a concordância sobre a necessidade de se instituir a união político-econômica dos países que dela fazem parte, englobando o engajamento dos governos para encaminhar os desafios produzidos pela diversidade e as divergências linguísticas, culturais e sociais (cf. BUSSE, 2017, p. 53, HU, 2016, p. 13; KRUMM, 2016ª p. 46).

Tomando a diversidade linguística como um dos desafios para a consolidação da referida articulação entre os países europeus, nota-se que o estreitamento desta cooperação depende em grande medida de um fator específico: do domínio de línguas estrangeiras pela população (cf. TUCCI / WAGNER, 2003). A importância destes conhecimentos é tão grande que os chefes de estado da União Europeia (UE) determinaram em 2002 o "objetivo de Barcelona": segundo este, cada cidadão europeu deveria saber comunicar-se em pelo menos duas línguas, além da língua materna ${ }^{11}$ (cf.

somente em seis dos dezesseis estados alemães e em algumas escolas (cf. Melo-Pfeifer 2016: 532).

${ }^{11}$ Este objetivo ainda não se reflete nas convicções dos alunos que, com frequência, argumentam que conhecimentos do inglês seriam suficientes. Este habitus monolingual, que simplifica sobremaneira a complexa realidade linguística 


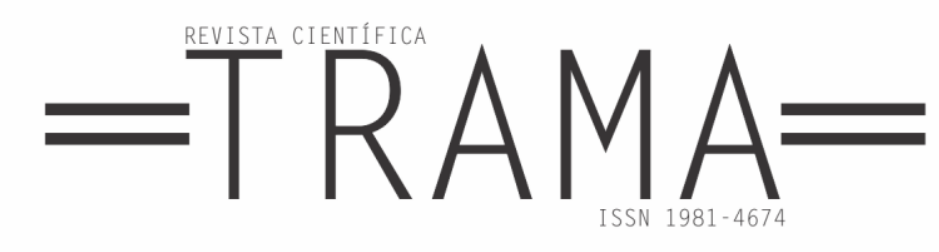

BUSSE, 2017, p. 53; KRUMM, 2016ª p. 47; KRUMM, 2016b, p. 635). Tal medida não é surpreendente, já que as principais instituições europeias, a saber, o Conselho da Europa e a UE ${ }^{12}$, definem cada vez mais a forma e as abordagens da aprendizagem de línguas estrangeiras (cf. KRUMM, 2016b, p. 633). Neste sentido, pode-se citar algumas medidas:

- A criação, desde 1999, de um espaço comum das instituições de educação superior (que inclui, entre outros aspectos, o reconhecimento de créditos e de diplomas de outras instituições) (cf. SCHÜTTE, 2015, p. 145);

- O funcionamento de instituições ligadas à aprendizagem e à pesquisa de línguas, como por exemplo, o Centro Europeu de Linguas Estrangeiras (cf. KRUMM, 2016b, p. 634);

- A elaboração de programas e de bolsas para mobilidade, tais como o programa Erasmus (cf. KRUMM, 2016a , p. 46; KRUMM, 2016b, p. $635)$;

- O fomento consciente e ativo do multilinguismo (cf. KRUMM, 2016a, p. 47);

- A utilização de inúmeros instrumentos e materiais de apoio à aprendizagem de línguas estrangeiras, tais como as descrições de competências

com a qual convivemos diariamente, ainda está presente nas aulas de muitas escolas e mostra que para a implantação de políticas linguísticas efetivas falta ainda um longo percurso (cf. Krumm 2016 : 49; Busse 2017: 68f.).

12 Dados os fins a que se propõe este artigo, não caberia discorrer sobre os pormenores intrínsecos ao funcionamento das duas instituições mencionadas. Para verificar a descrição detalhada a respeito do assunto, recomenda-se consultar o artigo de Krumm (2016b).

${ }^{13}$ O Quadro Europeu, publicado em 2001 pelo Conselho da Europa, foi discutido no mundo inteiro e traduzido para 38 línguas diferentes (cf. Krumm 2016b: 634). Trata-se, sem dúvida alguma, de um documento base para compreensão linguísticas, o portfólio de línguas, o passaporte de línguas ou - certamente o mais conhecido - o Quadro Comum Europeu para a Aprendizagem de Línguas ${ }^{13}$ (cf. HU 2016, p. 12; KRUMM, 2016b, p. 634f.; QUETZ, 2010, p. 45).

- As políticas públicas de fomento às línguas estrangeiras, portanto, podem ser impactantes e dependem de diversos fatores, incluindo a valorização do professor, cuja ocorrência é constatada quando observamos os dados referentes à remuneração destes profissionais: nos países membros da $\mathrm{OCDE}^{14}$, o salário de um professor do Ensino Médio chega, em média, a 31.000 dólares por ano. É interessante notar que nos países de língua alemã, a remuneração é consideravelmente mais alta, chegando a 35.000 dólares na Áustria, 55.000 dólares na Alemanha e 60.000 dólares na Suíça ${ }^{15}$ (cf. OCDE, 2016, p. 526f.).

Por outro lado, cabe ressaltar que o papel do professor tem passado por mudanças: este profissional deixa de atuar como um "professor isolado, de atitude monolingual" para se tornar, através do uso de competências didáticas e pedagógicas, um conselheiro para realidades heterogêneas e multilinguais (cf. HU,

dos processos de ensino e aprendizagem de línguas estrangeiras (cf. Quetz 2010: 45).

14 A Organização de Cooperação e Desenvolvimento Econômico, fundada em 1949, é formada por 35 países atualmente. A maioria dos membros é considerado "país desenvolvido".

${ }^{15}$ Este último dado evidencia um contraste acentuado: no Brasil, um professor ganha, em média, $25 \%$ da remuneração de um profissional na Alemanha ou na Suíça. As despesas na área educacional apontam para as mesmas diferenças: incluindo o investimento em todos os níveis do campo educacional, o Brasil gasta em torno de 4.318 dólares por aluno, enquanto este valor sobe para 11.545 dólares na Alemanha, 14.361 dólares na Áustria e 19.052 dólares na Suíça (cf. OCDE 2016: 227, 244). 


\section{$=$ TRAMA $=$}

2016, p. 14; ZIERER, 2016, p. 85). Novamente, as organizações europeias exercem forte influência nas abordagens direcionadas à formação de professores de línguas, por intermédio de instrumentos como o Quadro Europeu do Perfil de Docentes de Línguas (EPR) e o Portfólio Europeu de Professores de Línguas em Formação (EPOSA) (cf. KRUMM, 2016b, p. 636).

\section{Fomento do multilinguismo}

A tendência na Europa - como na maioria dos países do mundo - está direcionada à ampliação do espaço da língua inglesa nas instituições de ensino e na sociedade. A Alemanha, por sua vez, não foge desta tendência mundial. Por conseguinte, as crianças começam a aprender inglês cada vez mais cedo (cf. BUSSE, 2017, p. 54; RYMARCZYK, VOGT, 2016, p. 65). Com este pano de fundo, poder-se-ia fazer a seguinte pergunta: por que não considerar o inglês como língua principal e se limitar à aprendizagem deste idioma? Os políticos europeus, entretanto, optaram conscientemente por uma tendência inversa desde os anos 1960: preferiram dar importância para a aprendizagem do maior número possível de línguas (cf. QUETZ, 2010, p. 45). Tal escolha é consequência do acordo em que vale o equilíbrio entre os países da Europa, sem que se beneficie alguns, em detrimento de outros.

Outros argumentos que indicam a inclinação europeia para o fomento da aprendizagem de línguas seriam:

- Conhecimentos de várias línguas beneficiariam a economia, já que principalmente em áreas de comércio e de engenharias é essencial dominar a

\footnotetext{
${ }^{16}$ A obrigatoriedade das línguas estrangeiras é uma particularidade da Alemanha e de alguns outros países, principalmente europeus: mais de
}

língua dos clientes para ter acesso aos mercados (cf. TUCCI, WAGNER, 2003, p. 612).

- Línguas transportam o amplo conhecimento das sociedades. $\mathrm{Na}$ "era do conhecimento" (HALLET, 2006, p. 8-11; SCHÜTTE, 2015, p. 143), limitar-se a uma língua só significa fechar o acesso a um conhecimento específico.

- Em termos gerais, o conhecimento de línguas estrangeiras é um requisito indispensável para a internacionalização - seja esta uma medida das universidades, das empresas privadas ou de organizações públicas.

Tendo em vista este posicionamento da comunidade europeia, notamos que a importância dada ao multilinguismo virou consenso na Europa e deixou seu legado nos países-membros que ainda são responsáveis pela organização de seus próprios sistemas educativos. Colocando em foco o setor escolar da Alemanha, pode-se demonstrar de que maneira as ideias do multilinguismo influenciam as políticas públicas de educação:

- Em todos os tipos de escola os alunos aprendem, obrigatoriamente, duas línguas estrangeiras. Usualmente, o tempo mínimo de aprendizagem é cinco anos para a primeira LE, e três anos para a segunda ${ }^{16}$ (cf. RYMARCZYK, VOGT, 2016, p. 68).

- Além das aulas obrigatórias, muitas escolas oferecem disciplinas facultativas de LE, de forma que boa parte dos alunos entra em contato com uma terceira ou quarta língua estrangeira, antes mesmo de concluir o Ensino Médio. Através do uso de estratégias de aprendizagem, as experiências linguísticas podem ser aproveitadas para aprender rapidamente outros

$50 \%$ dos jovens de toda a Europa aprendem no mínimo duas línguas estrangeiras na escola (cf. Busse 2017: 56). 


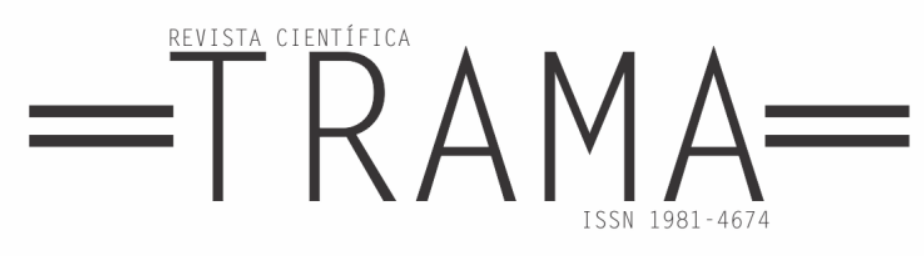

idiomas estrangeiros e aprofundá-los no futuro ${ }^{17}$.

- Os grupos de alunos nas aulas de línguas estrangeiras são relativamente pequenos: na Alemanha, um professor de línguas tem em média 13 alunos na sala, enquanto no Brasil este número é quase duas vezes mais alto (cf. OCDE, 2016, p. 510).

- Às línguas estrangeiras são destinadas maior carga horária de aulas. Se contabilizarmos aproximadamente 7.500 horas de aula para toda a escolaridade de um aluno na Europa, a Alemanha dedica aproximadamente $18 \%$ deste tempo ao ensino de línguas estrangeiras, chegando assim a quase 1.500 horas de aula. É um dos valores mais elevados no mundo (cf. OCDE, 2016, p. 503).

- O Ensino Médio na Alemanha é composto por cursos optativos: as matérias principais (Leistungskurs), onde línguas estrangeiras são elegíveis, têm usualmente cinco horasaula por semana e incluem frequentemente viagens a um país da línguaalvo.

- Mesmo depois de terminar a escola, os cidadãos têm acesso fácil à aprendizagem de línguas estrangeiras por várias vias, por exemplo através das já mencionadas Volkshochschulen.

É perceptível, portanto, que o fácil acesso à aprendizagem de línguas estrangeiras é reflexo tanto de uma política proativa de aprendizagem de línguas quanto da valorização cada vez maior que a sociedade atribui às competências linguísticas: o conhecimento de outros idiomas é considerado uma "competên-

\footnotetext{
${ }^{17}$ Conforme já foi mencionado anteriormente, a língua portuguesa quase não é ministrada como idioma curricular nas escolas da Alemanha (cf. Melo-Pfeifer 2016: 532). Sendo assim, cabe frisar que as pessoas que aprendem português como língua estrangeira na Alemanha sempre adquiriram, no mínimo, duas outras línguas antes.
}

cia básica" da educação das pessoas, instrumento indispensável para qualificação profissional, assim como a atitude aberta, tolerante e cosmopolita ${ }^{18}$ (cf. BUSSE, 2017, p. 62; TUCCI, WAGNER, 2003, p. 614.). Dominar idiomas estrangeiros também é cada vez mais importante no cenário dos movimentos migratórios, sejam eles de imigração ou de emigração. Os fenômenos são conhecidos no mundo inteiro, mas ganharam influência particularmente grande na Alemanha que presenciou, principalmente nos últimos dois anos, a chegada de grande contingente de refugiados. Diante disso, as entidades políticas formularam políticas públicas, cujos objetivos a serem atingidos nos cursos de línguas destinam-se à "criação de atitudes positivas frente à heterogeneidade cultural e linguística" (cf. BUSSE, 2017, p. 54).

Paralelamente, podemos observar aumento nas pesquisas acadêmicas sobre o tema: há aproximadamente 30 anos os fenômenos do multilinguismo estão sendo pesquisados pela perspectiva de várias disciplinas científicas (cf. RÖSLER, 2012, p. 8; HU, 2016, p. 11). Porém, nos últimos dois anos houve na Alemanha uma erupção de pesquisas, principalmente na área de ALE, devido à chegada de centenas de milhares de refugiados em pouco tempo. Saber lidar com as diferenças culturais - e com o desafio da aprendizagem de línguas - será sem dúvida uma competência crucial para que um país como a Alemanha possa enfrentar as próximas décadas com êxito.

\footnotetext{
${ }^{18}$ Está claro que na Europa não é todo mundo que quer ou que consegue aprender uma outra língua, e que a descrição é, de certa forma, idealizada. Entretanto, pode-se constatar um aumento considerável das habilidades linguísticas dos cidadãos europeus, nas últimas duas décadas (cf. Europäische Kommission 2012: 8).
} 


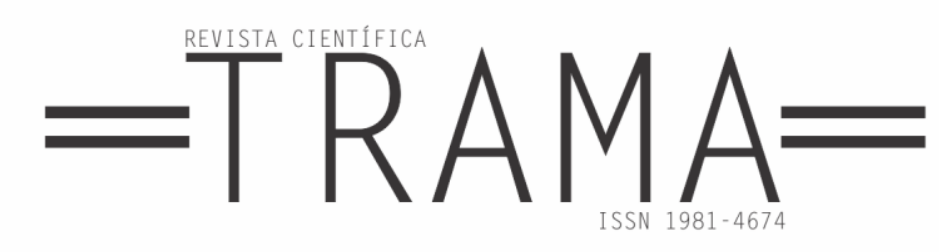

\section{desafio de "saber atuar" na língua estrangeira}

As observações realizadas neste artigo deixam claro que a competência linguística não é vista como mero "ornamento educativo", mas que no caso da Alemanha sua utilidade prática no dia-adia das pessoas é de grande relevância. Devido às curtas distâncias entre os países ${ }^{19}$ e às consequências da política europeia de aproximação econômica, política e cultural dos povos, há cada vez mais encontros entre pessoas com línguas maternas diferentes que têm a necessidade de saber comunicar-se com êxito entre si. Nestas situações de contato, o objetivo principal das aulas de Língua estrangeira (LE) muda do uso gramaticalmente correto da língua estrangeira ao fomento das habilidades comunicativas e interculturais dos interlocutores (cf. HU, 2016, p. 11).

Neste contexto encontramos justificativas para a prevalência das abordagens atuais nas aulas de LE. Estas seguem atualmente critérios gerais de dinâmicas positivas em sala de aula e são acompanhadas de "princípios didáticosmetodológicos" endógenos às aulas de idiomas estrangeiros (cf. KLIPPEL, 2016, p. 316). Alguns destes princípios são, por exemplo:

- O papel decisivo do construtivismo: as atividades próprias e autônomas realizadas por parte dos alunos, produzem aprendizagem aprofundada e eficiente. Este fato justifica a escolha por misturas equilibradas entre atividades dedutivas e indutivas em sala de aula (cf. FUNK, 2015, p. 34).

- Orientação às competências linguísticas, sendo o objetivo principal o domínio da língua-alvo: saber utilizá-la

19 Concretamente, a superfície da Alemanha equivale ao estado do Mato Grosso do Sul. Há fronteiras diretas com nove países e seis idiomas em situações de contato (cf. KLIPPEL, 2016, p. 317). Esta tendência explica o número elevado de exercícios orais e comunicativos nos materiais didáticos elaborados atualmente na Alemanha, que visivelmente influenciam o estilo e os objetivos da aula (cf. FUNK, 2015, p.33).

- Nos dias de hoje, as aulas de LE ministradas na Europa geralmente seguem aos princípios comunicativos. Com esta tendência, a fluidez da língua é considerada, em termos gerais, mais importante que o uso correto das estruturas gramaticais. Esta perspectiva exerce forte influência sobre as pautas das aulas, a seleção dos exercícios e tarefas e a forma de passar conteúdos de gramática (cf. FUNK, 2015, p. 32; KLIPPEL, 2016, p. 318).

Neste contexto vale a pena lembrar que os alunos só podem dominar aquilo que aprenderam e colocaram em prática. Consequentemente, é importante considerar que se o objetivo principal de aulas de língua estrangeira é possibilitar que os alunos possam atuar e se comunicar naquele idioma, é imprescindível oferecer atividades comunicativas durante as aulas, que implicariam interação ativa do aluno (cf. ENDE ET AL, 2013, p. 27.).

Estas convicções em defesa de uma aula comunicativa deixam sua marca na formação de professores, já que esta parte do pressuposto de que o docente deve saber tanto atuar na línguaalvo, quanto refletir sobre a dinâmica e os acontecimentos em sala de aula (cf. ENDE ET AL, 2013, p. 27). Da mesma maneira, deveríamos estar atentos para a atitude dos professores frente à línguaalvo: se os docentes atuam como multi-

estrangeiros. Cruzar o país inteiro de carro não demora mais de dez horas. 


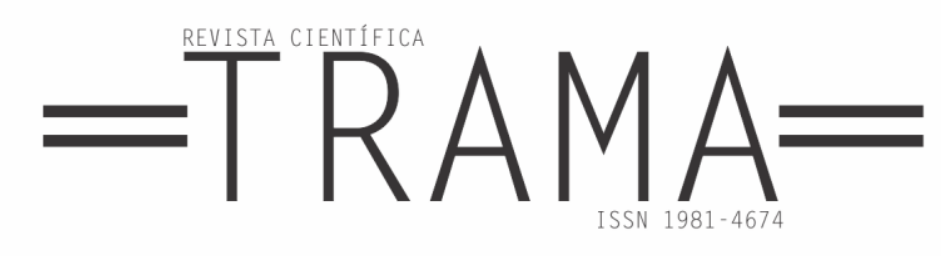

plicadores para expandir a língua e a cultura-alvo, sua dedicação é decisiva para semear nos alunos a motivação de aprender um idioma estrangeiro (cf. BUSSE, 2017 , p. 58, 66). Neste contexto, é clara a importância dada pela sociedade às questões concernentes ao fomento de línguas, assim como a relevância das políticas linguísticas enquanto parte do currículo da formação de professores, pois são fatores que determinam profundamente o cenário de aprendizagem de línguas (cf. KRUMM, 2016a, p. 50).

\section{Considerações finais}

Ao longo deste artigo argumentamos que o bom domínio de línguas estrangeiras não é pura coincidência, nem fruto de um talento inato dos europeus, mas que depende de uma série de fatores, como formação e remuneração dos professores, do número de alunos em sala de aula, do prestígio dado às línguas estrangeiras e da motivação para aprendê-las, de políticas públicas que apoiam (ou não) a aprendizagem, assim como da biografia linguística e da sequência na aprendizagem de idiomas. Observando a interdependência destes fatores e o peso das políticas públicas da educação, desenvolvidas na Alemanha ao longo das últimas décadas, não faria sentido propor que o Brasil reproduzisse uma por uma as medidas vigentes na Alemanha aplicadas ao campo da aprendizagem de línguas estrangeiras. Seria menos justificado ainda quando lembramos que para grande parte da população, ainda na atualidade, o maior obstáculo à aprendizagem de línguas estrangeiras no país não é a falta de motivação, mas sim o acesso à educação consistentemente estruturada (cf. RICHTER, 2013, p. 187).

Cabe ainda ressaltar que o multilinguismo é uma realidade cotidiana na maioria dos países do mundo (cf. HU,
2016, p.10). Aliás, apesar do Brasil ter perdido mais de 800 línguas desde a época da colonização, ele ainda é um país plurilíngue e pluricultural, com milhões de falantes de línguas autóctones e alóctones (cf. DORNELLES, 2011, p. 25-30). Dadas essas circunstâncias, se as orientações políticas tiverem por objetivo a promoção do monolinguismo, estaríamos diante não só da negação da realidade, mas também a um passo do retrocesso. Se um país pretende se diversificar, estreitar os laços com outros países e crescer economicamente, e se quiser ainda fazer parte da "era do conhecimento" - apostar em uma língua só seria uma tendência fatal (cf. SCHÜTTE, 2015, p. 143).

Frente a este cenário poderiam surgir questões sobre o posicionamento que o Brasil pretende tomar em matéria de políticas linguísticas e de educação. $\mathrm{O}$ ideal seria que a classe política dialogasse com os profissionais que estão a par das discussões sobre o tema, estabelecendo contato com as associações de professores de alemão ou a Associação de Estudos Germanísticos.

Ao retomar a exposição realizada neste trabalho, conclui-se que o domínio de línguas estrangeiras em determinada sociedade depende de muitos fatores. Através da apresentação da situação da Alemanha no contexto europeu, ressaltamos a importância particular de um deles: políticas linguísticas proativas planejadas a longo prazo são definitivamente imprescindíveis para obtenção de resultados positivos na área, seja no Brasil ou em outros países do mundo. 


\section{$=$ TRAMA $=$}

$\mathbf{R}_{\text {eferências }}$

BUSSE, Vera. Zur Förderung positiver Einstellungen gegenüber sprachlicher Diversität als europäisches Bildungsziel: Status quo und Desiderate. In: Zeitschrift für Fremdsprachenforschung (ZFF), 28: 1, 2017, pg. 53-75.

DE CILLIA, Rudolf; KLIPPEL, Friederike. Geschichte des Fremdsprachenunterrichts in deutschsprachigen Ländern seit 1945. In: BURWITZ-MELZER et al. (eds.). Handbuch Fremdsprachenunterricht. Tübingen: Francke, 2016, pg. 625-631.

DORNELLES, Clara. Brasil, um país monolíngue de todos? In: SILVA, Sidney (ed.). Línguas em contato. Cenários de Bilinguísmo no Brasil. Campinas: Pontes, 2011, pg. 25-38.

ENDE, Karin; GROTJAHN, Rüdiger; KLEPPIN, Karin; MOHR, Imke. Curriculare Vorgaben und Unterrichtsplanung. München: KlettLangenscheidt, 2013.

EUROPÄISCHE KOMMISSION. Erste Europäische Erhebung zur Fremdsprachenkompetenz.

Zusammenfassung der Ergebnisse. 2012. Disponível em: http://ec.europa.eu/dgs/education_culture/re pository/languages/

library/studies/executive-summaryeslc_de.pdf (Acesso em 19.11.2017).

FUNK, Hermann. Grammatikdidaktik, Neurowissenschaften und Fremdsprachenunterricht $\quad-$ populäre Irrtümer und hilfreiche Modelle. In: MOURA, Magali; SALIÉS, Tânia; STANKE, Roberta; BOLACIO, Ebal (eds.). Ensino-aprendizagem de alemão como língua estrangeira: teoria e práxis. [Volume 2]. Rio de Janeiro: Letra Capital, 2015, pg. 30-46.

GUASCO PEIXOTO, Madalena. O público e o privado na história da educação brasileira. In: Revista Princípios, $\mathrm{n}^{\circ} 123$ (fevereiro-março 2013), pg. 103-109.

HALLET, Wolfgang. Didaktische Kompetenzen. Lehr- und Lernprozesse erfolgreich gestalten. Stuttgart, Klett, 2006. HU, Adelheid. Mehrsprachigkeit. In: BURWITZ-MELZER et al. (eds.).
Handbuch Fremdsprachenunterricht. Tübingen: Francke, 2016, pg. 10-15. HUNEKE, Hans Werner; STEINIG, Wolfgang. Deutsch als Fremdsprache. Eine Einführung. Berlin: Erich Schmidt, 2013.

JOFFILY, Bernardo. Três motivos de fundo para investir o pré-sal na educação. In: Revista Princípios, $\mathrm{n}^{\circ} 125$ (junho-julho 2013), pg. 66-70.

KAUFMANN, Göz. Deutsch und Germanistik in Brasilien. In: Jahrbuch für internationale Germanistik. Jahrgang XXXV (2003) / Heft 1, pg. 29-39.

KLIPPEL, Friederike. Didaktische und methodische Prinzipien der Vermittlung. In: BURWITZ-MELZER et al. (eds.). Handbuch Fremdsprachenunterricht. Tübingen: Francke, 2016, pg. 315-320.

KRUMM, Hans-Jürgen (2016a): Sprachenpolitik und das Lernen und Lehren von Sprachen. In: BURWITZ-MELZER et al. (eds.). Handbuch Fremdsprachenunterricht. Tübingen: Francke, 2016, pg. 45-51.

KRUMM, Hans-Jürgen (2016b): Förderung des Lehrens und Lernens von Sprachen durch Europarat und Europäische Union. In: BURWITZ-MELZER et al. (eds.). Handbuch Fremdsprachenunterricht. Tübingen: Francke, 2016, pg. 633-637. MELO-PFEIFER, Sílvia. Portugiesisch. In: BURWITZ-MELZER et al. (eds.). Handbuch Fremdsprachenunterricht. Tübingen: Francke, 2016, pg. 530-534.

OCDE. Bildung auf einen Blick 2016. OECD-Indikatoren. Paris: OECD, 2016. [Deutsche Version Herausgegeben in Zusammenarbeit mit dem Bundesministerium für Bildung und Forschung - BMBF]. Disponível em: https://www.bmbf.de/files/Educa-

tion_at_a_Glance_2016.pdf (Acesso em: 31.08.2017).

PRECHT, Richard David. Anna, die Schule und der liebe Gott. München: Goldmann, 2013.

QUETZ, Jürgen. Gemeinsamer europäischer Referenzrahmen. In: HALLET, Wolfgang; KÖNIGS, Frank (eds.). Handbuch Fremdsprachendidaktik. Seelze: Klett Kallmeyer, 2010, pg. 45-49. 


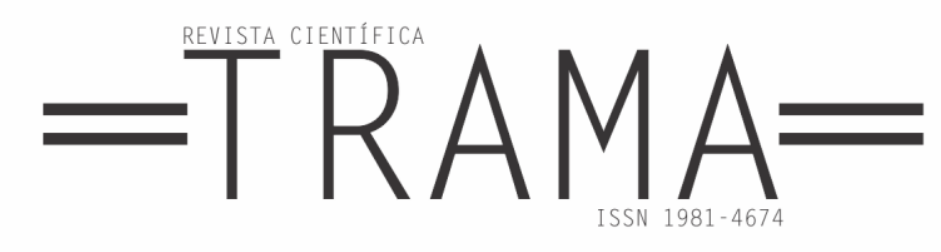

REINFRIED, Marcus. Geschichte des Fremdsprachenunterrichts bis 1945. In: BURWITZ-MELZER et al. (eds.). Handbuch Fremdsprachenunterricht. Tübingen: Francke, 2016, pg. 619-625.

RICHTER, Claudia. Das Bildungswesen in Brasilien. In: ADICK, Christel (ed.). Bildungsentwicklungen und Schulsysteme in Afrika, Asien, Lateinamerika und der Karibik. Münster: Waxmann, 2013, pg. 171-189.

ROCHE, Jörg. Fremdsprachenerwerb, Fremdsprachendidaktik. Tübingen: Narr Francke Attempto, 2008. RÖSLER, Dietmar. Deutsch als Fremdsprache. Eine Einführung. Stuttgart: Metzler, 2012.

RYMARCZYK, Jutta; VOGT, Karin. Sprachen lernen und lehren im Elementarund Schulbereich. In: BURWITZ-MELZER et al. (eds.). Handbuch Fremdsprachenunterricht. Tübingen: Francke, 2016, pg. 65-70.

SCHÜTTE, Georg. Internationalisierung, Exzellenz, Wettbewerb - Hochschule und Wissenschaft im globalen Spannungsfeld. In: MAAß, Kurt-Jürgen (ed.). Kultur und Außenpolitik. Handbuch für Wissenschaft und Praxis. Baden-Baden: Nomos, 2015, pg. 135-148.

SUPREMO TRIBUNAL FEDERAL. Constituição da República Federal do Brasil. Atualizada até a EC n. 96/2017. Brasília, 2017.

TUCCI, Ingrid; WAGNER, Gert. Fremdsprachenkenntnisse als wichtige Zusatzqualifikation im Dienstleistungssektor. In: Wochenbericht des DIW Berlin. 70. Jahrgang, Nr. 41/2003, pg. 611-615. Disponível em: http://www.academia.edu/25686211/Fremd sprachenkenntnisse_als_wichtige_Zusatzqu alifikation_im_Dienstleistungssektor (Acesso em: 31.08.2017).

ZIERER, Klaus. Hattie für gestresste Lehrer. Baltmannsweiler: Schneider Verlag Hohengehren, 2016. 